\section{The glycogen synthase gene in NIDDM and hypertension}

Dear Sir,

Both in non-insulin-dependent diabetes mellitus (NIDDM) and essential hypertension, insulin resistance appears to be genetically determined and mainly observed in the non-oxidative pathway (i.e. glycogen synthesis) in skeletal muscle [1,2]. Glycogen synthase (GSY), a key enzyme of the non-oxidative pathway of glucose metabolism, may be a candidate gene for insulin resistance in NIDDM and hypertension. In fact, an association between a rare $A_{2}$ allele of the Xbal polymorphism in the GSY gene and NIDDM has recently been reported among a group of Finnish patients [3]. Moreover, a high prevalence of hypertension was also reported in subjects with Xbal RFLP. These data implicated the GSY gene as a candidate for genetic predisposition to hypertension as well as NIDDM. This association, however, was not confirmed by subsequent studies in other ethnic groups [4-6]. Furthermore, association studies between hypertension and the GSY gene have not yet been reported.

In this letter, we present our study on the association of the GSY locus with both NIDDM and hypertension using a sensitive fluorescence detection method. A total of 193 subjects (72 patients with NIDDM, 66 patients with essential hypertension and 55 non-diabetic healthy subjects) were studied. The hypertensive subjects were divided into two groups (hyperinsulinaemia group and normoinsulinaemia group) according to their insulin levels during 75-g oral glucose tolerance test (OGTT) (hyperinsulinaemia: a peak insulin level during 75-g $\mathrm{OGTT}>100 \mathrm{mU} / \mathrm{l})$. Patients who showed a diabetic pattern were excluded from the hypertensive group. The non-diabetic healthy subjects were normotensive, with normal glucose tolerance, and had no family history of diabetes or hypertension. All subjects in this study had body mass index (BMI) less than $30 \mathrm{~kg} / \mathrm{m}^{2}$. A microsatellite polymorphism in the GSY gene was detected by the method of Vionnet and Bell [7] with modification. One of the primers was labelled with rhodamine instead of ${ }^{32} \mathrm{P}$ in the original method, and electrophoretic pat-

Corresponding author: Dr. H. Ikegami, Department of Geriatric Medicine, Osaka University Medical School, 2-2 Yamadaoka, Suita, Osaka 565, Japan terns of the amplified fragments were imaged by scanning the gel plates with a fluorescence image analyser (FMBIO, Takara Shuzo, Kyoto, Japan).

Nine different alleles were detected in 193 unrelated subjects (Table 1). There was no significant difference in allele frequencies between control subjects and NIDDM patients as a whole or a subgroup of patients with positive family history of diabetes. Among 66 hypertensive patients, 21 were classified in the hyperinsulinaemia group and 45 in the normoinsulinaemia group. There was no difference in age, BMI, blood pressure and the incremental area of glucose during 75-g OGTT between the two groups. There was no significant difference in allele frequencies between hyperinsulinaemia and normoinsulinaemia groups or between these groups and the control group. These data suggest that the GSY locus is not associated with either NIDDM or hypertension even when the insulin-resistant subgroup was studied.

Previous reports indicated that most Japanese patients with NIDDM are characterized by impaired insulin secretion rather than hyperinsulinaemia, and this appears to precede the onset of diabetes [8], suggesting that an inherited defect in insulin secretion rather than in insulin action may be responsible for the genetic predisposition to NIDDM in the Japanese. Therefore, the absence of association of the GSY gene with NIDDM in Japanese patients is not surprising because GSY contributes to insulin resistance but not to insulin secretion. In fact, we and others reported that the glucokinase locus, which encodes a key enzyme in glucose-stimulated insulin secretion, is associated with NIDDM in Japanese [9, 10]. Lack of association of the GSY locus with Japanese NIDDM was also reported by one group [5], although another group reported a positive association [6]. The reason for the different results are unknown, but one possibility is a regional difference.

In conclusion, the microsatellite polymorphism in the GSY gene was not associated with NIDDM or hypertension, suggesting that this polymorphism is not a marker for NIDDM or hypertension in the Japanese. The GSY gene, however, may still be involved in the genetic predisposition to NIDDM and hypertension in a subgroup of patients with severe insulin resistance.

Yours sincerely,

Y.Hamada, H.Ikegami, Y.Fujioka, E. Yamato, K. Takekawa, T. Fujisawa, Y.Nakagawa, H. Ueda, J.Fu, G.-Q. Shen, T.Mild, T. Ogihara 
Table 1. Allele frequencies of the microsatellite polymorphism in the glycogen synthase gene

\begin{tabular}{lccccc}
\hline Allele & $\begin{array}{l}\text { Control subjects } \\
(n=110)\end{array}$ & $\begin{array}{l}\text { NIDDM subjects } \\
(n=144)\end{array}$ & \multicolumn{2}{l}{ Hypertensive subjects } \\
\cline { 4 - 6 } & & $\begin{array}{l}\text { Hyperinsulinaemia } \\
(n=42)\end{array}$ & $\begin{array}{l}\text { Normoinsulinaemia } \\
(n=90)\end{array}$ & Total $(n=132)$ \\
\hline$-3 \mathrm{G}$ & $5(4.5)$ & $10(6.9)$ & $2(4.8)$ & $0(0)$ & $2(1.5)$ \\
$-2 \mathrm{G}$ & $1(0.9)$ & $2(1.4)$ & $1(2.4)$ & $4(4.4)$ & $5(3.8)$ \\
$-1 \mathrm{G}$ & $7(6.4)$ & $3(2.1)$ & $16(38.1)$ & $34(37.8)$ & $11(8.3)$ \\
$0 \mathrm{G}$ & $48(43.6)$ & $54(37.5)$ & $12(28.6)$ & $24(26.7)$ & $36(27.9)$ \\
$1 \mathrm{G}$ & $22(20.0)$ & $38(26.4)$ & $7(16.7)$ & $13(14.4)$ & $20(15.2)$ \\
$2 \mathrm{G}$ & $25(22.7)$ & $30(20.8)$ & $1(2.4)$ & $6(6.7)$ & $7(5.3)$ \\
$3 \mathrm{G}$ & $2(1.8)$ & $5(3.5)$ & $0(0)$ & $1(1.1)$ & $1(0.8)$ \\
$4 \mathrm{G}$ & $0(0)$ & $1(0.7)$ & $0(0)$ & $0(0)$ & $0(0)$ \\
\hline 5
\end{tabular}

Values in parentheses are \% of total

\section{References}

1. Vaag A, Henriksen JE, Beck-Nielsen H (1992) Decreased insulin activation of glycogen synthase in skeletal muscles in young nonobese Caucasian first-degree relatives of patients with non-insulin-dependent diabetes mellitus. J Clin Invest 89: 782-788

2. Ferrannini E, Haffner SM, Stern MP (1990) Essential hy• pertension: an insulin-resistant state. J Cardiovasc Pharmacol 15 [Suppl 5]: S18-S25

3. Groop LC, Kankuri M, Schalin JC et al. (1993) Association between polymorphism of the glycogen synthase gene and non-insulin-dependent diabetes mellitus. $\mathrm{N}$ Engl J Med 328: 10-14

4. Elbein SC, Hoffman M, Ridinger D, Otterud B, Leppert M (1994) Description of a second microsatellite marker and linkage analysis of the muscle glycogen synthase locus in familial NIDDM. Diabetes 43: 1061-1065

5. Shimokawa K, Kadowaki H, Sakura H et al. (1994) Molecular scanning of the glycogen synthase and insulin receptor substrate-1 genes in Japanese subjects with non-insulin-dependent diabetes mellitus. Biochem Biophys Res Commun 202: 463-469
6. Kuroyama H, Sanke T, Ohagi S et al. (1994) Simple tandem repeat DNA polymorphism in the human glycogen synthase gene is associated with NIDDM in Japanese subjects. Diabetologia 37: 536-539

7. Vionnet N, Bell GI (1993) Identification of a simple tandem repeat DNA polymorphism in the human glycogen synthase gene and linkage of five markers on chromosome 19q. Diabetes 42: 930-932

8. Kadowaki T, Miyake Y, Hagura R et al. (1984) Risk factors for worsening to diabetes in subjects with impaired glucose tolerance. Diabetologia 26: 44-49

9. Noda K, Matsutani A, Tanizawa Y et al. (1993) Polymorphic microsatellite repeat markers at the glucokinase gene locus are positively associated with NIDDM in Japanese. Diabetes 42: 1147-1152

10. Takekawa K, Ikegami H, Fukuda M et al. (1994) Early-onset type 2 (non-insulin-dependent) diabetes mellitus is associated with glucokinase locus, but not with adenosine deaminase locus, in the Japanese population. Diabetes Res Clin Pract 23: 141-146 